\title{
The Level of the Functional Movement Screen Among Traditional Dancers
}

\author{
Segar A. Maniveloo ${ }^{1}$, Borhannudin Abdullah ${ }^{1}$, Shamsulariffin Samsudin ${ }^{1}$ \\ ${ }^{1}$ Department of Sports Studies, Faculty of Educational Studies, Universiti Putra Malaysia, Serdang, Malaysia \\ Correspondence: Shamsulariffin Samsudin, Department of Sports Studies, Faculty of Educational Studies, \\ Universiti Putra Malaysia, 43400 UPM Serdang Selangor, Malaysia. Tel: 603-9769-8210. E-mail: \\ shamariffin@upm.edu.my
}

Received: September 3, $2021 \quad$ Accepted: September 28, $2021 \quad$ Online Published: October 15, 2021

doi:10.5539/ass.v17n11p103

URL: https://doi.org/10.5539/ass.v17n11p103

\begin{abstract}
Movement assessments are commonly used to assess athlete's risk of injury as well as basic and specific skill movement patterns; however, dance is identified to be differing from sports because the average dancer's training load is higher than the athletes. This study aims to identify the difference in the Functional Movement Screen (FMS) level among traditional dancers in Malaysia. A quasi-experimental study design was adopted, which involved 66 dancers $(\mathrm{M}=33 ; \mathrm{F}=33)$. The study comprised traditional dancers from three ethnic backgrounds, namely, Malay, Chinese and Indian. The descriptive analysis described the level of the dancers' FMS, as follows: Malay $(\mathrm{M}=16.18, \mathrm{SD}=2.062)$, Chinese $(\mathrm{M}=18.50, \mathrm{SD}=1.102)$, Indian $(\mathrm{M}=18.23, \mathrm{SD}=$ 1.445). The ANOVA analysis found a significant difference in the FMS scores among all three groups of dancers, $\mathrm{F}(2,63)=14.026, \mathrm{p}>.000$. The deep squat, hurdle step, shoulder mobility, active straight leg raise and trunk stability tests for push-up indicated a significant difference, whereas the inline lunges test and rotational stability tests showed no significance difference. However, the Post Hoc analysis showed no significant difference between the Chinese and Indian dancers. It can be concluded that there is a difference in FMS scores between Malay, Chinese and Indian dancers. FMS may be a useful tool to help identify dancers about the risk of injury and improve their movement quality.
\end{abstract}

Keywords: Functional Movement Screen, FMS, Traditional Dancers

\section{Introduction}

\subsection{Research Background}

A movement assessment serves to assess the quality of a person's basic movements. This movement assessment involves all the major muscles and joints in the body such as the spine and pelvic bones. This testing method is commonly used by physiotherapists, physicians, and coaches to assess the risks of injury and movement patterns of basic and specific skills of athletes (Conlon, 2013). The Functional Movement Screen (FMS) is an initial assessment performed on athletes by physical therapists to identify weaknesses and qualities in their movement patterns (Cook, Burton, \& Hoognboom, 2006). It is also user-friendly, has a low-cost as well as a reliable tool, which has gained attention from researchers and physical therapists since its development (Smith, Chimera, Wright, \& Warren, 2013). FMS consists of seven movements or tests to assess namely deep squats, hurdle steps, inline lunges, shoulder mobility, active straight leg raise, trunk stability push-ups and rotary stability. To perform all these movements, participants need muscle strength, flexibility, coordination, balance, range of motion and proprioception of specific joint mobility as well as a standardized movement system (Cook et al., 2006). Deficiency of one of these elements will result in an increased risk of muscle and joint injuries (Frost, Beach, Callaghan, \& McGill, 2012). According to Lockie, Schultz, Jordan, Callaghan, Jeffriess, and Luczo (2015), FMS is not only used to predict injuries, but also it seems to have low efficacy in identifying movement weaknesses in complex movements ranging from fast movements from multiple directions and jumping.

\subsection{Research Problem}

FMS has been used by many researchers to identify injury risks in a wide variety of populations (Lisman, O’Connor, Deuster, \& Knapik, 2013). This test is important for predicting injuries in different populations of both athletes and non-athletes because the roles played are different during early recovery (Cosio-Lima, Knapik, 
Shumway, Reynolds, Lee, Greska, \& Hampton, 2016). Although dance is admittedly different from other sports, it is surprising that the average weekly training load involved in dance is higher than that of football athletes in one season (Rogalski, Dawson, Heasman, \& Gabbett, 2013). A study has been conducted and utilized a limited study population using female university contemporary and ballet dancers shown the lack of studies comparing movement assessment tests between various traditional dances of different ethnicities and genders prompted the author to conduct this study (Armstrong, 2020). Over the years, dancers perform repetitive movements to master the skills and quality of their performance (Shah, Weiss, \& Burchette, 2012). This tires the dancer and makes them prone to injury. Dance-related injury rates are reported to average between 67-95\% annually (Fuhrmann, Brayer, Andrus, \& McIntosh, 2010).

Due to the high percentage of injuries, professionals in the field of dance science have sought to understand the biomechanics of dance to promote injury prevention in elite dancers. While attention is growing in studies, most focus has been placed on ballet dancers. Hence, researchers have highlighted the need for more research to be done on injuries and their consequences in various dances. Leg and ankle injuries are common, and sprains on the ankle are common among traditional dancers (Leanderson, Leanderson, Wykman, Strender, Johansson, \& Sundquist, 2011). The three most frequently reported diagnoses in professional traditional dancers were muscle tension (28\%), sprained ligament (23\%) and chronic pain such as tendonitis and bursitis (21\%) (Shah et al., 2012). According to Kenny, Palacios-Derflingher, Shi, Whittaker and Emery (2019) lower body injuries in dancers and sports athletes are practically identical, involving ligament and overuse. This was proven when Bharatanatyam dancers recorded back injuries about $42.5 \%$, knee injuries of $28.3 \%$ and $18.63 \%$ of ankle injuries throughout their careers and injuries throughout their lifetime (Masal \& Borkar, 2021). The majority of dance injuries were classified as overuse injuries, which occurred as a result of physical activity that was not followed by proper recovery periods.

An imbalance between training load and rehabilitation training results in fatigue and leads to injury (Soligard et al., 2016). A better understanding of injuries and movement analysis for dancers should be conducted to help in the planning and preparation of a systematic training design to prevent overuse injuries (Armstrong, 2020). As stated in a recent study by Armstrong (2020), it is important to examine movement quality and injury risk in dancers of different ethnic backgrounds to determine the level of risk in dance. However in Malaysia, this research focuses on 3 major ethnic's dances such as Malay, Chinese and Indian and also very limited studies in the field of dance and FMS. Additionally, this research is also important prior to help sports scientists to compare the differences of traditional dance with fitness components such as flexibility and body coordination. Therefore, it is necessary to understand that FMS is not only for assessing the extent of the injury, the recovery process and the development of gross motor skills but also more than that. When the movement quality of a dancer has been improved with good training techniques, it may help the dancers to improve specific performance techniques with their basic performance and at the same time help them to perform better during competitions or performances and get better results. There are very limited studies on analysis of movement and screening of injuries in dance, especially in traditional dances among various races. To add on, most of the studies are focused mainly on western society dances such as ballet and contemporary dance.

\subsection{Literature Review}

Compared to other professions, a professional dancer's career time frame is generally shorter. Dancers who suffer injuries have to spend their time in recovering and they may miss auditions, lose their salaries, or lose their contracts, which could also mean the end of their careers (Solomon, Solomon, Micheli, \& McGray, 1999). Most dance injuries are chronic and occur in the lower body and hips, and the risk factors for these injuries are ascribed to a lack of strength in the abdominal muscles (core stability) (Rickman, Ambegaonkar \& Cortes, 2012). Dance is a high-intensity physical activity that requires a lot of energy and as such, puts dancers at a high risk of experiencing musculoskeletal injuries.

Dancers spend at least 1.5 hours in their daily classes, which is coupled with longer and more time-consuming performance training (Miller, 2006). Teen dancers can increase their training for about 20 to 30 hours per week when they become pre-professional, and this will continue to increase as they enhance to professional levels due to the high skill requirements (Wyon et al., 2004). Establishing and implementing effective assessment tools can positively impact dancers' physical and mental health by allowing them to dance with a low risk of injury (Armstrong \& Relph, 2018). However, developing movement assessment batteries in dance is much more difficult compared to sports because dance is more artistic and emotional (Liederbach, 1997).

Since the development of the FMS, studies have been conducted with many athletes, including professional athletes in specific sports, university athletes, high school students, and even athletes such as firefighters and 
military to determine and predict injury risk. Nevertheless, there was modest evidence shown that FMS test results can identify and predict injury risk (Kazman et al., 2014). This test is important for predicting injury in different populations, whether they are athletes or non-athletes, because of the different roles they play in the early recovery stage (Cosio-Lima et al., 2016). Despite that, FMS works to help trainers understand the importance of implementing basic movement training types to improve movement patterns (Boguszewski, Jakubowska, Adamczyk, \& Bialoszewski, 2015).

\subsection{Significance of the Study}

Most FMS studies are on the same population of athletes, and there is very little research in the area of dance, especially traditional dance. Dancers need to have a better understanding about movement assessment tools in order to perform better. For instance, research findings on dancers' FMS levels can help coaches provide appropriate training programs based on dance type. A good training program can reduce dance injuries such as overuse and fatigue. Therefore, the main purpose of this research is to identify FMS level among Malay, Chinese and Indian dancers. Moreover, it is also purposed to determine the difference between FMS scores and the seven test scores in FMS among Malay, Chinese and Indian dancers.

\section{Method}

\subsection{Research Design}

This research utilizes a quantitative survey study research design to identify and compare the differences in the FMS scores among Malay, Chinese and Indian traditional dancers.

\subsection{Study Population}

This study used purposive sampling, which involved individual judgment in selecting the sample. This was based on research knowledge and the specific purpose of the research (Noraini, 2013). The sample of this study involved a sample size consisting of 66 dancers that were divided into 3 groups of dancers. Each group had 22 dancers who were equally divided according to gender. The number of subjects in this study was determined through GPower device version 3.1. Subjects were selected based on several set criteria such as dancers active in dance schools and clubs, who train at least six hours a week, have experience in dance for five years and above, free from any injuries and who are over the age of 18 years.

\subsection{Research Instrument}

The main instrument used in this study was the Functional Movement Screen (FMS) developed by Cook, Burton, Fields and Kiesel (1998). FMS consists of behaviours tested in the following sequences such as deep squats, hurdle steps, inline lunges, shoulder mobility, active straight leg raise, trunk stability push-ups and rotary stability. All exercises were performed bilaterally except the deep squats and trunk stability push-ups. Each FMS action was scored on a scale of 0 to 3 according to the ability and movement of the subjects. Subjects who experienced pain while performing three clearing tests, namely shoulder mobility, trunk stability push-ups and rotary stability, obtained a score of 0 for the exercise. For acts done bilaterally, scores were recorded for both sides, but only the lowest score was considered. The final score for each action was summed up to obtain the total score and the maximum score that could be recorded is 21 points.

\subsection{Data Analysis}

The data collected was processed using the Statistical Package for Social Sciences (SPSS) version 20. Data analysis was performed using descriptive statistics and the ANOVA test to identify differences in the level of FMS among Malay, Chinese and Indian dancers. The alpha value was set at $\mathrm{p}<0.05$ to explain the statistical significance of the comparison.

\section{Results}

\subsection{Level of FMS Scores Among Malay, Chinese and Indian Dancers}

Firstly, the analysis of the descriptive study on FMS scores level among Malay, Chinese and Indian traditional dancers were recorded. Chinese dancers recorded the highest FMS score mean $(\mathrm{SD})$ with $(\mathrm{M}=18.50, \mathrm{SD}=$ $1.102)$, followed by Indian dancers at $(\mathrm{M}=18.23, \mathrm{SD}=1.445)$ and Malay dancers recorded the lowest at $(\mathrm{M}=$ $16.18, \mathrm{SD}=2.062)$. Malay dancers had the highest score in inline lunges $(\mathrm{M}=2.68, \mathrm{SD}=.477)$ and the lowest score in the trunk stability push-ups $(\mathrm{M}=1.86, \mathrm{SD}=.710)$. For Chinese dancers, they recorded the highest score in active straight leg raise $(\mathrm{M}=3.00, \mathrm{SD}=.000)$ and the lowest score in trunk stability push-ups $(\mathrm{M}=2.27, \mathrm{SD}$ $=.631)$. Meanwhile, Indian dancers recorded the highest score in deep squats $(\mathrm{M}=2.86, \mathrm{SD}=.351)$ as well as active straight leg raise $(\mathrm{M}=2.86, \mathrm{SD}=.351)$ and the lowest score in rotary stability $(\mathrm{M}=2.14, \mathrm{SD}=.468)$. Mean scores showed all three groups recorded low scores in the push-up trunk stability test. 
Table 1. Descriptive Analysis of FMS Score Among Malay, Chinese and Indian Dancers

\begin{tabular}{|c|c|c|c|c|}
\hline Ethnicity & Variable & $\mathrm{N}$ & Mean & SD \\
\hline \multirow{8}{*}{ Malay } & Deep Squat & 22 & 2.45 & .596 \\
\hline & Hurdle Step & 22 & 2.18 & .501 \\
\hline & Inline Lunges & 22 & 2.68 & .477 \\
\hline & Shoulder Mobility & 22 & 2.41 & .666 \\
\hline & Active Straight Leg Raise & 22 & 2.59 & .503 \\
\hline & Trunk Stability Push up & 22 & 1.86 & .710 \\
\hline & Rotary Stability & 22 & 2.00 & .436 \\
\hline & Total & 22 & 16.18 & 2.062 \\
\hline \multirow{8}{*}{ Chinese } & Deep Squat & 22 & 2.32 & .477 \\
\hline & Hurdle Step & 22 & 2.82 & .395 \\
\hline & Inline Lunges & 22 & 2.73 & .456 \\
\hline & Shoulder Mobility & 22 & 2.91 & .294 \\
\hline & Active Straight Leg Raise & 22 & 3.00 & .000 \\
\hline & Trunk Stability Push up & 22 & 2.27 & .631 \\
\hline & Rotary Stability & 22 & 2.32 & .477 \\
\hline & Total & 22 & 18.50 & 1.102 \\
\hline \multirow{8}{*}{ Indian } & Deep Squat & 22 & 2.86 & .351 \\
\hline & Hurdle Step & 22 & 2.45 & .510 \\
\hline & Inline Lunges & 22 & 2.77 & .429 \\
\hline & Shoulder Mobility & 22 & 2.77 & .429 \\
\hline & Active Straight Leg Raise & 22 & 2.86 & .351 \\
\hline & Trunk Stability Push up & 22 & 2.36 & .658 \\
\hline & Rotary Stability & 22 & 2.14 & .468 \\
\hline & Total & 22 & 18.23 & 1.445 \\
\hline
\end{tabular}

\subsection{Differences in FMS Scores Among Malay, Chinese and Indian Dancers}

Table 2. ANOVA Analysis on FMS Score among Malay, Chinese and Indian Dancers

\begin{tabular}{cccccc}
\hline & Sum of Squares & df & Mean Square & F & Sig. \\
\hline Between Groups & 70.636 & 2 & 35.318 & 14.026 & .000 \\
Within Groups & 158.636 & 63 & 2.518 & & \\
Total & 229.273 & 65 & & & \\
\hline
\end{tabular}

Table 3. Post Hoc Test Analysis on FMS Score among Malay, Chinese and Indian Dancers Dependent Variable: FMS Score

Tukey HSD

\begin{tabular}{|c|c|c|c|c|c|c|}
\hline \multirow{2}{*}{ (I) Ethnicity } & \multirow{2}{*}{ (J) Ethnicity } & \multirow{2}{*}{$\begin{array}{c}\text { Mean Difference } \\
(\mathrm{I}-\mathrm{J})\end{array}$} & \multirow{2}{*}{ Std. Error } & \multirow{2}{*}{ Sig. } & \multicolumn{2}{|c|}{ 95\% Confidence Interval } \\
\hline & & & & & Lower Bound & Upper Bound \\
\hline \multirow{2}{*}{ Malay } & Chinese & $-2.318^{*}$ & .478 & .000 & -3.47 & -1.17 \\
\hline & Indian & $-2.045^{*}$ & .478 & .000 & -3.19 & -.90 \\
\hline \multirow{2}{*}{ Chinese } & Melayu & $2.318^{*}$ & .478 & .000 & 1.17 & 3.47 \\
\hline & Indian & .273 & .478 & .837 & -.88 & 1.42 \\
\hline \multirow{2}{*}{ Indian } & Malay & $2.045^{*}$ & .478 & .000 & .90 & 3.19 \\
\hline & Chinese & -.273 & .478 & .837 & -1.42 & .88 \\
\hline
\end{tabular}

*. The mean difference is significant at the 0.05 level.

Mean (SD) FMS acting for Chinese dancers was $(\mathrm{M}=18.50, \mathrm{SD}=1.102)$ and Indian dancers was $(\mathrm{M}=18.23$, $\mathrm{SD}=1.445)$, which were higher than the Malay dancers at $(\mathrm{M}=16.18, \mathrm{SD}=2.062)$. The total mean $(\mathrm{SD})$ of 
FMS for the three groups was $(M=17.64, \mathrm{SD}=1.878)$. There were significant differences between the FMS scores among Malay, Chinese and Indians dancers, F $(2,63)=14.026, p>.000$. However, the Post Hoc Test results found that only Malay with Chinese dancers $(\mathrm{p}<.000)$ and Malay with Indian dancers $(\mathrm{p}<.000)$ had significant differences with a mean difference of 2.318 and 2.045 .

\subsection{Differences in Deep Squat Scores Among Malay, Chinese and Indian Dancers}

The mean score $(\mathrm{SD})$ of deep squats for Indian dancers was $(\mathrm{M}=2.86, \mathrm{SD}=.351)$ and Malay dancers was $(\mathrm{M}=$ $2.45, \mathrm{SD}=.596)$, which were higher than the Chinese dancers, which was $(\mathrm{M}=2.32, \mathrm{SD}=.477)$. The total mean $(\mathrm{SD})$ for deep squats was $(\mathrm{M}=2.55, \mathrm{SD}=.532)$. The hypothesis of this study stated that there were significant differences between the deep squats among Malay, Chinese and Indian dancers, F $(2,63)=7.537, \mathrm{p}<.001$. However, the results of the Post Hoc Test found that only Chinese and Indians dancers had a significant difference of $\mathrm{p}<.001$, with a mean difference of 0.545 .

Table 4. ANOVA Test Analysis of Deep Squat Score among Malay, Chinese and Indian Dancers

\begin{tabular}{cccccc}
\hline & Sum of Squares & df & Mean Square & F & Sig. \\
\hline Between Groups & 3.545 & 2 & 1.773 & 7.537 & .001 \\
Within Groups & 14.818 & 63 & .235 & & \\
Total & 18.364 & 65 & & & \\
\hline
\end{tabular}

Table 5. Post Hoc Test Analysis of Deep Squat Score among Malay, Chinese and Indian Dancers

Dependent Variable: Deep Squat

Tukey HSD

\begin{tabular}{ccccccc}
\hline \multirow{2}{*}{ (I) Ethnicity } & \multirow{2}{*}{ (J) Ethnicity } & \multirow{2}{*}{ Mean Difference (I-J) } & \multirow{2}{*}{ Std. Error } & \multirow{2}{*}{ Sig. } & \multicolumn{2}{c}{$95 \%$ Confidence Interval } \\
\cline { 5 - 7 } Malay & Chinese & .136 & .146 & .622 & -.21 & .49 \\
& Indian & $-.409^{*}$ & .146 & .018 & -.76 & -.06 \\
& Malay & -.136 & .146 & .622 & -.49 & .21 \\
\multirow{3}{*}{ Chinese } & Indian & $-.545^{*}$ & .146 & .001 & -.90 & -.19 \\
& Malay & $.409^{*}$ & .146 & .018 & .06 & .76 \\
& Chinese & $.545^{*}$ & .146 & .001 & .19 & .90 \\
\hline
\end{tabular}

*. The mean difference is significant at the 0.05 level.

\subsection{Differences in the Hurdle Step Scores Among Malay, Chinese and Indian Dancers}

Table 6. ANOVA Test Analysis of Hurdle Step Score among Malay, Chinese and Indian Dancers

\begin{tabular}{cccccc}
\hline & Sum of Squares & df & Mean Square & F & Sig. \\
\hline Between Groups & 4.485 & 2 & 2.242 & 10.091 & .000 \\
Within Groups & 14.000 & 63 & .222 & & \\
Total & 18.485 & 65 & & & \\
\hline
\end{tabular}

Table 7. Post Hoc Test Analysis of Hurdle Step Score among Malay, Chinese and Indian Dancers

Dependent Variable: Hurdle Step

Tukey HSD

\begin{tabular}{|c|c|c|c|c|c|c|}
\hline \multirow{2}{*}{ (I) Ethnicity } & \multirow{2}{*}{ (J) Ethnicity } & \multirow{2}{*}{$\begin{array}{c}\text { Mean Difference } \\
(\mathrm{I}-\mathrm{J})\end{array}$} & \multirow{2}{*}{ Std. Error } & \multirow{2}{*}{ Sig. } & \multicolumn{2}{|c|}{ 95\% Confidence Interval } \\
\hline & & & & & Lower Bound & Upper Bound \\
\hline \multirow{2}{*}{ Malay } & Chinese & $-.636^{*}$ & .142 & .000 & -.98 & -.30 \\
\hline & Indian & -.273 & .142 & .142 & -.61 & .07 \\
\hline \multirow{2}{*}{ Chinese } & Malay & $.636^{*}$ & .142 & .000 & .30 & .98 \\
\hline & Indian & $.364^{*}$ & .142 & .034 & .02 & .70 \\
\hline \multirow{2}{*}{ Indian } & Malay & .273 & .142 & .142 & -.07 & .61 \\
\hline & Chinese & $-.364^{*}$ & .142 & .034 & -.70 & -.02 \\
\hline
\end{tabular}

*. The mean difference is significant at the 0.05 level. 
The mean score $(\mathrm{SD})$ of hurdle steps for Chinese dancers was $(\mathrm{M}=2.82, \mathrm{SD}=.395)$ and Indian dancers was $(\mathrm{M}$ $=2.45, \mathrm{SD}=.510)$, which were higher than the Malay dancers at $(\mathrm{M}=2.18, \mathrm{SD}=.501)$. The total mean $(\mathrm{SD})$ for hurdle steps was $(\mathrm{M}=2.48, \mathrm{SD}=.533)$. The hypothesis of this study stated that there were significant differences between the scores of hurdle steps among Malay, Chinese and Indian dancers, F $(2,63)=10.091$, p $<.000$. However, the Post Hoc Test results found that only Malays with Chinese dancers ( $\mathrm{p}<.000)$ and China with India dancers ( $\mathrm{p}<.034)$ had significant differences with a mean difference of 0.636 and 0.364 .

\subsection{Differences in the Inline Lunges Scores Among Malay, Chinese and Indian Dancers}

The mean score $(\mathrm{SD})$ of inline lunges for Indian dancer was $(\mathrm{M}=2.77, \mathrm{SD}=.429)$ and Chinese dancers was (M $=2.73, \mathrm{SD}=.456)$, higher than the Malay dancers which was $(\mathrm{M}=2.68, \mathrm{SD}=.477)$. The total mean $(\mathrm{SD})$ for inline lunges was $(\mathrm{M}=2.73, \mathrm{SD}=.449)$. The hypothesis of this study indicated that there were no significant differences between the inline lunges among Malay, Chinese and Indian dancers, F $(2,63)=.220, \mathrm{p}>.803$. Likewise, Post Hoc Test results also found no significant differences between the dancers. The mean difference for both Malay and Chinese dancers with Indian and Chinese dancers was 0.045 and Malay with Indian dancers was 0.091 .

Table 8. ANOVA Test Analysis of Inline Lunges Score among Malay, Chinese and Indian Dancers

\begin{tabular}{cccccc}
\hline & Sum of Squares & df & Mean Square & F & Sig. \\
\hline Between Groups & .091 & 2 & .045 & .220 & .803 \\
Within Groups & 13.000 & 63 & .206 & & \\
Total & 13.091 & 65 & & \\
\hline
\end{tabular}

Table 9. Post Hoc Test Analysis of Inline Lunges Score among Malay, Chinese and Indian Dancers

Dependent Variable: Inline Lunges

Tukey HSD

\begin{tabular}{|c|c|c|c|c|c|c|}
\hline \multirow{2}{*}{ (I) Ethnicity } & \multirow{2}{*}{ (J) Ethnicity } & \multirow{2}{*}{$\begin{array}{c}\text { Mean Difference } \\
\text { (I-J) }\end{array}$} & \multirow{2}{*}{ Std. Error } & \multirow{2}{*}{ Sig. } & \multicolumn{2}{|c|}{ 95\% Confidence Interval } \\
\hline & & & & & Lower Bound & Upper Bound \\
\hline \multirow{2}{*}{ Malay } & Chinese & -.045 & .137 & .941 & -.37 & .28 \\
\hline & Indian & -.091 & .137 & .785 & -.42 & .24 \\
\hline \multirow{2}{*}{ Chinese } & Malay & .045 & .137 & .941 & -.28 & .37 \\
\hline & Indian & -.045 & .137 & .941 & -.37 & .28 \\
\hline \multirow{2}{*}{ Indian } & Malay & .091 & .137 & .785 & -.24 & .42 \\
\hline & Chinese & .045 & .137 & .941 & -.28 & .37 \\
\hline
\end{tabular}

*. The mean difference is significant at the 0.05 level

\subsection{Differences in the Shoulder Mobility Scores Among Malay, Chinese and Indian Dancers}

The mean score $(\mathrm{SD})$ of shoulder mobility for Chinese dancers was $(\mathrm{M}=2.91, \mathrm{SD}=.294)$ and for Indian dancers was $(\mathrm{M}=2.77, \mathrm{SD}=.429)$, higher than the Malay dancers which was $(\mathrm{M}=2.41, \mathrm{SD}=.666)$. The total mean (SD) for shoulder mobility was $(\mathrm{M}=2.70, \mathrm{SD}=.525)$. The hypothesis of this study stated that there were significant differences between the scores of shoulder mobility among Malay, Chinese and Indian dancers, F $(2,63)=6.173, \mathrm{p}<.004$. However, the Post Hoc Test results found that only Malay and Chinese dancers $(\mathrm{p}<.003)$ with Malay and Indian dancers $(\mathrm{p}<.042)$ had significant differences with a mean difference of 0.500 and 0.364 .

Table 10. ANOVA Test Analysis of Shoulder Mobility Score among Malay, Chinese and Indian Dancers

\begin{tabular}{cccccc}
\hline & Sum of Squares & df & Mean Square & F & Sig. \\
\hline Between Groups & 2.939 & 2 & 1.470 & 6.173 & .004 \\
Within Groups & 15.000 & 63 & .238 & & \\
Total & 17.939 & 65 & & & \\
\hline
\end{tabular}


Table 11. Post Hoc Test Analysis of Shoulder Mobility Score among Malay, Chinese and Indian Dancers Dependent Variable: Shoulder Mobility

Tukey HSD

\begin{tabular}{ccccccc}
\hline \multirow{2}{*}{ (I) Ethnicity } & \multirow{2}{*}{ (J) Ethnicity } & $\begin{array}{c}\text { Mean Difference } \\
\text { Mal-J) }\end{array}$ & \multirow{2}{*}{ Std. Error } & Sig. & \multicolumn{2}{c}{$95 \%$ Confidence Interval } \\
\cline { 5 - 7 } & Chinese & $-.500^{*}$ & .147 & .003 & -.85 & -.15 \\
& Indian & $-.364^{*}$ & .147 & .042 & -.72 & -.01 \\
\multirow{2}{*}{ Chinese } & Malay & $.500^{*}$ & .147 & .003 & .15 & .85 \\
& Indian & .136 & .147 & .625 & -.22 & .49 \\
\multirow{2}{*}{ Indian } & Malay & $.364^{*}$ & .147 & .042 & .01 & .72 \\
& Chinese & -.136 & .147 & .625 & -.49 & .22 \\
\hline
\end{tabular}

*. The mean difference is significant at the 0.05 level.

\subsection{Differences in Active Straight Leg Raise Scores Among Malay, Chinese and Indian Dancers}

The mean score $(\mathrm{SD})$ for active straight leg raise for Chinese dancers was $(\mathrm{M}=3.00, \mathrm{SD}=.000)$ and Indian dancers was $(\mathrm{M}=2.86, \mathrm{SD}=.351)$, higher than the Malay dancers which was $(\mathrm{M}=2.59, \mathrm{SD}=.503)$. The total mean $(\mathrm{SD})$ for active straight leg raise is $(\mathrm{M}=2.82, \mathrm{SD}=.389)$. The hypothesis of this study stated that there were significant differences in scores of active straight legs raise among Malay, Chinese and Indian dancers, $\mathrm{F}$ $(2,63)=7.603, p<.001$. However, the Post Hoc Test results found that only Malay with Chinese dancers ( $p$ $<.001)$ and Malay with Indian dancers $(\mathrm{p}<.035)$ had significant differences with a mean difference of 0.409 and 0.273 .

Table 12. ANOVA Test Analysis of Active Straight Leg Raise Score among Malay, Chinese and Indian Dancers

\begin{tabular}{cccccc}
\hline & Sum of Squares & df & Mean Square & F & Sig. \\
\hline Between Groups & 1.909 & 2 & .955 & 7.603 & .001 \\
Within Groups & 7.909 & 63 & .126 & & \\
Total & 9.818 & 65 & & & \\
\hline
\end{tabular}

Table 13. Post Hoc Test Analysis of Active Straight Leg Raise Score among Malay, Chinese and Indian Dancers

Dependent Variable: Active Straight Leg Raise

Tukey HSD

\begin{tabular}{|c|c|c|c|c|c|c|}
\hline \multirow{2}{*}{ (I) Ethnicity } & \multirow{2}{*}{ (J) Ethnicity } & \multirow{2}{*}{$\begin{array}{c}\text { Mean Difference } \\
(\mathrm{I}-\mathrm{J})\end{array}$} & \multirow{2}{*}{ Std. Error } & \multirow{2}{*}{ Sig. } & \multicolumn{2}{|c|}{ 95\% Confidence Interval } \\
\hline & & & & & Lower Bound & Upper Bound \\
\hline \multirow{2}{*}{ Malay } & Chinese & $-.409^{*}$ & .107 & .001 & -.67 & -.15 \\
\hline & Indian & $-.273^{*}$ & .107 & .035 & -.53 & -.02 \\
\hline \multirow{2}{*}{ Chinese } & Malay & $.409^{*}$ & .107 & .001 & .15 & .67 \\
\hline & Indian & .136 & .107 & .414 & -.12 & .39 \\
\hline \multirow{2}{*}{ Indian } & Malay & $.273^{*}$ & .107 & .035 & .02 & .53 \\
\hline & Chinese & -.136 & .107 & .414 & -.39 & .12 \\
\hline
\end{tabular}

*. The mean difference is significant at the 0.05 level.

\subsection{Differences in the Trunk Stability Push-up Scores Among Malay, Chinese and Indian Dancers}

The mean score (SD) of trunk stability push-ups for Indian dancers was $(\mathrm{M}=2.36, \mathrm{SD}=.658)$ and Chinese dancers was $(\mathrm{M}=2.27, \mathrm{SD}=.631)$, higher than the Malay dancers which was $(\mathrm{M}=1.86, \mathrm{SD}=.710)$. The total mean (SD) for the push-up stability trunk was $(\mathrm{M}=2.17, \mathrm{SD}=.692)$. The hypothesis of this study stated that there were significant differences between the scores of trunk stability push-ups among Malay, Chinese and Indian dancers, $\mathrm{F}(2,63)=3.506, \mathrm{p}<.036$. However, the Post Hoc Test results found that only Malay and Indian dancers had significant differences $\mathrm{p}<.041$, with a mean difference of 0.500 . 
Table 14. ANOVA Test Analysis of Trunk Stability Push-Up Score among Malay, Chinese and Indian Dancers

\begin{tabular}{cccccc}
\hline & Sum of Squares & df & Mean Square & F & Sig. \\
\hline Between Groups & 3.121 & 2 & 1.561 & 3.506 & .036 \\
Within Groups & 28.045 & 63 & .445 & & \\
Total & 31.167 & 65 & & & \\
\hline
\end{tabular}

Table 15. Post Hoc Test Analysis of Trunk Stability Push-Up Score among Malay, Chinese and Indian Dancers Dependent Variable: Trunk Stability Push up Tukey HSD

\begin{tabular}{ccccccc}
\hline \multirow{2}{*}{ (I) Ethnicity } & (J) Ethnicity & \multirow{2}{*}{ Mean Difference (I-J) } & \multirow{2}{*}{ Std. Error } & \multirow{2}{*}{ Sig. } & \multicolumn{2}{c}{$95 \%$ Confidence Interval } \\
\cline { 6 - 8 } & & & & & Lower Bound & Upper Bound \\
\hline \multirow{2}{*}{ Malay } & Chinese & -.409 & .201 & .113 & -.89 & .07 \\
& Indian & $-.500^{*}$ & .201 & .041 & -.98 & -.02 \\
\hline \multirow{2}{*}{ Chinese } & Malay & .409 & .201 & .113 & -.07 & .89 \\
& Indian & -.091 & .201 & .894 & -.57 & .39 \\
\hline \multirow{2}{*}{ Indian } & Malay & $.500^{*}$ & .201 & .041 & .02 & .98 \\
& Chinese & .091 & .201 & .894 & -.39 & .57 \\
\hline
\end{tabular}

*. The mean difference is significant at the 0.05 level.

\subsection{Difference in the Rotary Stability Scores Among Malay, Chinese and Indian Dancers}

The mean score $(\mathrm{SD})$ of rotary stability for Chinese dancers was $(\mathrm{M}=2.32, \mathrm{SD}=.477)$ and India dancers was $(\mathrm{M}=2.14, \mathrm{SD}=.468)$, higher than Malay dancers which was $(\mathrm{M}=2.00, \mathrm{SD}=.436)$. The total mean $(\mathrm{SD})$ for rotary stability is $(\mathrm{M}=2.15, \mathrm{SD}=.472)$. The hypothesis of this study stated that there were no significant differences between the score of rotary stability among Malay, Chinese and Indian dancers, F $(2,63)=2.643$, p> .079. Similarly, Post Hoc Test found no significant differences between dancers. The mean difference between Malay with Chinese dancers was 0.318, Indian with Chinese dancers was 0.182 and Malay with Indian dancers was 0.136 .

Table 16. ANOVA Test Analysis of Rotary Stability Score among Malay, Chinese and Indian Dancers

\begin{tabular}{cccccc}
\hline & Sum of Squares & df & Mean Square & F & Sig. \\
\hline Between Groups & 1.121 & 2 & .561 & 2.643 & .079 \\
Within Groups & 13.364 & 63 & .212 & & \\
Total & 14.485 & 65 & & & \\
\hline
\end{tabular}

Table 17. Post Hoc Test Analysis of Rotary Stability Score among Malay, Chinese and Indian Dancers Dependent Variable: Rotary Stability

Tukey HSD

\begin{tabular}{ccccccc}
\hline \multirow{2}{*}{ (I) Ethnicity } & (J) Ethnicity & Mean Difference (I-J) & Std. Error & \multirow{2}{*}{ Sig. } & \multicolumn{2}{c}{$95 \%$ Confidence Interval } \\
\cline { 6 - 7 } Malay & Chinese & -.318 & .139 & .064 & -.65 & .02 \\
& Indian & -.136 & .139 & .591 & -.47 & .20 \\
& Malay & .318 & .139 & .064 & -.02 & .65 \\
\multirow{2}{*}{ Chinese } & Indian & .182 & .139 & .395 & -.15 & .52 \\
& Malay & .136 & .139 & .591 & -.20 & .47 \\
& Chinese & -.182 & .139 & .395 & -.52 & .15 \\
\hline
\end{tabular}

*. The mean difference is significant at the 0.05 level.

\section{Discussion and Conclusion}

4.1 Discussion

The FMS is a set of tests developed to assess an individual's dynamic movement capacity as well as to detect 
injuries and the quality of their movement (Cook et al., 2006 (1)). Studies related to performance and injuries among different populations are needed to reduce the number of dancers who suffer injuries, which may end their careers as a dancer (Armstrong, 2020). The findings showed that there was a significant difference of $p$ $<.000$ between the three groups of dancers in terms of the FMS score. However, through the Post Hoc test, it was found that there was no significant difference between Chinese and Indian dancers. Chinese dancers recorded the highest mean (18:50) compared to the Malay and Indian dancers. This showed a significant difference between Malay with Chinese dancers and Malay with Indian dancers, probably because Chinese and Indian dance have much in common in terms of the FMS tests such as gait, "Namaskaram" in Bharatanatyam and the squat style of the Lion Dance. This was supported by Fernandez-Arguelles, Rodriguez-Mansilla, Antunez, Garrido-Ardila and Munoz (2015) where they stated that dance is closely associated with improved balance, muscle strength, coordination, rhythm, and body control. This combination is found only in a few types of dances and mostly consists of classical dances from various ethnicities and races.

Lower body injuries are defined as injuries to the lower butt, calves, thighs, knees, fingers, and ankles (Van Seters, Van Rijn, Van Middelkoop, \& Stubbe, 2020). The findings showed a significant difference of a total p $<.001$ between the three groups of dancers for the deep squats score. However, the Post Hoc test showed no significant difference between Chinese and Malay dancers. Indian dancers recorded the highest mean (2.86) compared to Malay and Chinese dancers. The possible reason for this result could be the fact that the squat itself is one of the basic movements in Indian traditional dances such as Bharatanatyam and Kuchipudi, which is "Namaskaram". This was proven to be true when Bharatanatyam dancers recorded $42.5 \%$ lower back injuries, $28.3 \%$ knees injuries and $18.63 \%$ ankles injuries throughout their careers and lifelong injuries (Masal \& Borkar, 2021)

The findings showed that there was a significant difference of $\mathrm{p}<.000$ between the three groups of dancers for the hurdle step score. However, the Post Hoc test found no significant difference between Malay and Indian dancers. Chinese Dancers, however, recorded the highest mean (2.82) compared to Indian and Malay dancers. The mean difference between the Chinese and Malay dancers was very significant and this may be due to the movement of the Lion Dance, which requires dancers to stand on one leg. These findings are closely related to the study of Rickman et al., (2012) who stated that most injuries in dance are chronic and occur in the lower back and hips. Researchers also stated that the risk factor for this injury is due to the weakness of the abdominal muscles (core stability).

The findings showed no significant difference between the three groups of dancers for the score of inline lunges. The results of the Post Hoc test also found no significant difference of $p>.803$ between the three groups of dancers. The gap between the means is not that much, in which Indian dancers obtained the highest mean (2.77) and Malay dancers recorded the lowest mean (2.68). This may be because the dances of these three groups of dancers focus a lot on balance and stability skills in the Joget Dance, Lion Dance and Bharatanatyam. According to Phillips (2005), the level of stability and balance of a professional dancer is higher when compared to a professional athlete. This is because dance is more prone to extreme movements over a long period of time. He also noted that joint stability and passive structures are highly dependent on the quality of an individual's collagen tissue. These tissues form passive structures such as ligaments, knee capsules, fascia, and tendons.

According to Mengelkock, Highsmith and Morris (2014), upper body movement mobility is very important for a dancer to avoid injuries to the spine, pelvic bones, and shoulders. The findings showed that there was a significant difference of $\mathrm{p}<.004$ between the three groups of dancers for the shoulder mobility score. However, the Post Hoc test found no significant difference between Malay with Indian dancers and Chinese with Indian dancers. Chinese dancers recorded the highest mean (2.91) compared to Indian and Malay dancers. This may be due to upper body injuries involving the dancers' joints that they themselves have not yet identified. Motta-Valencia (2006) explained that most injuries affecting dancers are considered overuse injuries such as tendons and joints. This is closely related to the dances of these three groups, which prioritize extreme hand movements.

According to Shah et al., (2012), the majority of muscular injuries that occur involve the lower body where foot and ankle injuries recorded a high injury rate with $(20.5 \%-28.0 \%)$, knee $(16.0 \%-21.4 \%)$ and lower waist $(13.4 \%$ $-17.0 \%)$. The findings showed that there was a significant difference of $p<.001$ between the three groups of dancers for the active straight leg raise score. However, the Post Hoc test found no significant difference between Chinese and Indian dancers. Chinese dancers record the highest mean (3.00) compared to Indian and Malay dancers. All three groups recorded a good mean score, and this proved they had good flexibility and stability between the hamstrings and the pelvis. However, Kenny et al., (2019) noted that lower body injuries for dancers and sports athletes are almost identical and mostly involve ligaments and overuse factors. 
Dancers can vary the coordination of body movements compared to non-dancers; mainly in the upper and lower body sagittal planes, transverse as well as coronal (Jarvis, Smith, \& Kulig, 2014). The findings showed that there was a significant difference of $\mathrm{p}<.036$ between the three groups of dancers for the push-up trunk stability score. However, the Post Hoc test found no significant difference between Malay with Chinese dancers and Indian with Chinese dancers. Indian dancers recorded the highest mean (2.36) compared to Chinese and Malay dancers. Although this is closely related to coordination as well as anterior and posterior plane stability, muscle strength factors of the upper body may also play a role in the trunk stability push-ups. This finding was supported through a research by Lee, Reid, Cadwell and Palmer (2017) emphasized that muscle injuries are an ongoing health issue among pre-professional dancers and most of these injuries are due to overuse factors that come from repetitive movements.

According to Chang, Halaki, Adams, Cobley, Lee and O'Dwyer (2016), the combination of motor skills, coordination as well as speed of movement is a very important combination for a dancer to produce a good performance. The findings showed no significant difference between the three groups of dancers for the rotary stability score. The Post Hoc test results also found no significant difference of $p>.079$ between the three groups of dancers. The gap between the mean score was not much, in which Chinese dancers gained the highest mean (2.32) and Malay dancers obtained the lowest mean (2.00). Such results may be due to the level of neuromuscular coordination between the upper and lower body which is similar for all three groups. This finding was supported by Chang, O'Dwyer, Adams, Cobley, Lee and Halaki (2020) stated that the improvement of dancer skills and aesthetic value in dances may also be closely related to other factors such as level of neuromuscular coordination, dance smoothness and movement variation in the dance.

A specific test battery needs to be developed to test the quality of movement in dance that emphasizes training duration, dance history, physical testing, fitness, and complex dance movements. Developing a battery of movement assessments in dance is much more difficult when compared to sports because dance is more artistic and emotional (Liederbach, 1997). According to Newton (2002), needs analysis is a key step in the process of forming a good training program by a coach.

FMS can identify dancers who are at risk of injury. Therefore future studies could include subjects covering different types of dances, such as African American dance, social dance and street dance. This is important to determine the basic movement needs depending on the type of dance, as most traditional dances require flexibility, unlike African American dances that require muscular and cardiovascular endurance. Intervention training that focuses on flexibility, coordination, and muscle strength may also affect FMS scores. Moreover, the level of dancers such as professional and pre-professional dancers can also be a factor influencing movement evaluation scores.

\subsection{Conclusion}

According to the findings of this study, Chinese dancers recorded the highest scores in four of the seven FMS tests (hurdle step, shoulder mobility, active straight leg raise and rotary stability). Meanwhile, Indian dancers recorded the highest scores in three of the seven FMS tests (deep squats, inline lunges, and trunk stability push-ups). There is a significant FMS score difference between Malay, Chinese and Indian dancers. FMS may be a useful tool to help identify dancers at the risk of injury and improve their quality of movement. The findings of this study will help sports scientists to get more information about injuries in dance, especially traditional dance. This study is also the first in Malaysia to investigate the relationship between FMS and dance in Malaysia, and it is hoped that this study will serve as a benchmark for further FMS studies in Malaysia. The findings will also help trainers in developing training programs for specific dance styles, lowering the risk of injuries and improving dancers' movement quality.

\section{References}

Armstrong, R. (2020). The relationship between the functional movement screen, star excursion balance test and the Beighton score in dancers. The Physician and Sportsmedicine, 48(1), 53-62. https://doi.org/10.1080/00913847.2019.1624658

Armstrong, R., \& Relph, N. (2018). Screening tools as a predictor of injury in dance: Systematic literature review and meta-analysis. Sports Medicine-open, 4(1), 1-28. https://doi.org/10.1186/s40798-018-0146-z

Boguszewski, D., Jakubowska, K., Adamczyk, J. G., \& Białoszewski, D. (2015). The assessment of movement patterns of children practicing karate using the Functional Movement Screen test. Journal of Combat Sports and Martial Arts, 6(1), 21-26. https://doi.org/10.5604/20815735.1174227

Chang, M., Halaki, M., Adams, R., Cobley, S., Lee, K. Y., \& O'Dwyer, N. (2016). An exploration of the 
perception of dance and its relation to biomechanical motion: A systematic review and narrative synthesis. Journal of Dance Medicine \& Science, 20(3), 127-136. https://doi.org/10.12678/1089-313X.20.3.127

Chang, M., O'Dwyer, N., Adams, R., Cobley, S., Lee, K. Y., \& Halaki, M. (2020). Whole-body kinematics and coordination in a complex dance sequence: Differences across skill levels. Human movement science, 69, 102564. https://doi.org/10.1016/j.humov.2019.102564

Conlon, J. K. (2013). The Relationship Between the Functional Movement Screen ${ }^{\mathrm{TM}}$ and Countermovement Jump Height (Doctoral dissertation). The University of Wisconsin-Milwaukee.

Cook, G., Burton, L., \& Hoogenboom, B. (2006). Pre-participation screening: the use of fundamental movements as an assessment of function-part 1. North American Journal of Sports Physical Therapy: NAJSPT, 1(2), 62-72. PMCID: PMC2953313

Cook, G., Burton, L., \& Hoogenboom, B. (2006). Pre-participation screening: The use of fundamental movements as an assessment of function-part 2. North American Journal of Sports Physical Therapy: NAJSPT, 1(3), 132-139. PMCID: PMC2953359

Cook, G., Burton, L., Fields, K., \& Kiesel, K. B. (1998). The Functional Movement Screen. Athletic Testing Services. Inc.: Danville, CA, USA.

Cosio-Lima, L., Knapik, J. J., Shumway, R., Reynolds, K., Lee, Y., Greska, E., \& Hampton, M. (2016). Associations between functional movement screening, the $\mathrm{Y}$ balance test, and injuries in coast guard training. Military Medicine, 181(7), 643-648. https://doi.org/10.7205/MILMED-D-15-00208

Fernandez-Arguelles, E. L., Rodriguez-Mansilla, J., Antunez, L. E., Garrido-Ardila, E. M., \& Munoz, R. P. (2015). Effects of dancing on the risk of falling related factors of healthy older adults: A systematic review. Archives of Gerontology and Geriatrics, 60(1), 1-8. https://doi.org/10.1016/j.archger.2014.10.003

Frost, D. M., Beach, T. A., Callaghan, J. P., \& McGill, S. M. (2012). Using the Functional Movement Screen ${ }^{\text {TM }}$ to evaluate the effectiveness of training. The Journal of Strength \& Conditioning Research, 26(6), 1620-1630. https://doi.org/10.1519/JSC.0b013e318234ec59

Fuhrmann, T. L., Brayer, A., Andrus, N., \& McIntosh, S. (2010). Injury prevention for modern dancers: A pilot study of an educational intervention. Journal of Community Health, 35(5), 527-533. https://doi.org/10.1007/s10900-010-9223-z

Jarvis, D. N., Smith, J. A., \& Kulig, K. (2014). Trunk coordination in dancers and nondancers. Journal of applied biomechanics, 30(4), 547-554. https://doi.org/10.1123/jab.2013-0329

Kazman, J. B., Galecki, J. M., Lisman, P., Deuster, P. A., \& O'Connor, F. G. (2014). Factor structure of the functional movement screen in marine officer candidates. The Journal of Strength \& Conditioning Research, 28(3), 672-678. https://doi.org/10.1519/JSC.0b013e3182a6dd83

Kenny, S. J., Palacios-Derflingher, L., Shi, Q., Whittaker, J. L., \& Emery, C. A. (2019). Association between previous injury and risk factors for future injury in preprofessional ballet and contemporary dancers. Clinical Journal of Sport Medicine, 29(3), 209-217. https://doi.org/10.1097/JSM.0000000000000513

Leanderson, C., Leanderson, J., Wykman, A., Strender, L. E., Johansson, S. E., \& Sundquist, K. (2011). Musculoskeletal injuries in young ballet dancers. Knee Surgery, Sports Traumatology, Arthroscopy, 19(9), 1531-1535. https://doi.org/10.1007/s00167-011-1445-9

Lee, L., Reid, D., Cadwell, J., \& Palmer, P. (2017). Injury incidence, dance exposure and the use of the movement competency screen (MCS) to identify variables associated with injury in full-time pre-professional dancers. International Journal of Sports Physical Therapy, 12(3), 352. PMCID: PMC5455185

Liederbach, M. (1997). Screening for functional capacity in dancers designing standardized, dance-specific injury prevention screening tools. Journal of Dance Medicine \& Science, 1(3), 93-106.

Lisman, P., O’Connor, F. G., Deuster, P. A., \& Knapik, J. J. (2013). Functional movement screen and aerobic fitness predict injuries in military training. Medicine \& Science in Sports \& Exercise, 45(4), 636-643. https://doi.org/10.1249/MSS.0b013e31827a1c4c

Lockie, R. G., Schultz, A. B., Jordan, C. A., Callaghan, S. J., Jeffriess, M. D., \& Luczo, T. M. (2015). Can selected functional movement screen assessments be used to identify movement deficiencies that could affect multidirectional speed and jump performance?. The Journal of Strength \& Conditioning Research, 29(1), 195-205. https://doi.org/10.1519/JSC.0000000000000613 
Masal, S., \& Borkar, P. (2021). Epidemiology of musculoskeletal injuries in Indian classical dancers: A systematic review. International Journal of Physical Education, Sports and Health, 8(3), 310-319

Mengelkoch, L. J., Highsmith, M. J., \& Morris, M. L. (2014). Comparison of the metabolic demands of dance performance using three mobility devices for a dancer with spinal cord injury and an able-bodied dancer. Medical problems of performing artists, 29(3), 163-167. https://doi.org/10.21091/mppa.2014.3033

Miller, C. (2006). Dance medicine: Current concepts. Physical Medicine and Rehabilitation Clinics, 17(4), 803-811. https://doi.org/10.1016/j.pmr.2006.06.005

Motta-Valencia, K. (2006). Dance-related injury. Physical Medicine and Rehabilitation Clinics, 17(3), 697-723. https://doi.org/10.1016/j.pmr.2006.06.001

Newman, L. K. (2002). Sex, gender and culture: Issues in the definition, assessment and treatment of gender identity disorder. Clinical Child Psychology and Psychiatry, 7(3), 352-359. https://doi.org/10.1177\%2F1359104502007003004

Noraini, I. (2013). Penyelidikan dalam pendidikan (Edisi kedua). Kuala Lumpur: McGraw-Hill.

Phillips, C. (2005). Stability in dance training. Journal of dance medicine \& science, 9(1), 24-28.

Rickman, A. M., Ambegaonkar, J. P., \& Cortes, N. (2012). Core stability: Implications for dance injuries. Medical problems of performing artists, 27(3), 159-164. https://doi.org/10.21091/mppa.2012.3028

Rogalski, B., Dawson, B., Heasman, J., \& Gabbett, T. J. (2013). Training and game loads and injury risk in elite Australian footballers. Journal of Science and Medicine in Sport, 16(6), 499-503. https://doi.org/10.1016/j.jsams.2012.12.004

Shah, S., Weiss, D. S., \& Burchette, R. J. (2012). Injuries in professional modern dancers: Incidence, risk factors, and management. Journal of Dance Medicine \& Science, 16(1), 17-25.

Smith, C. A., Chimera, N. J., Wright, N. J., \& Warren, M. (2013). Interrater and intrarater reliability of the functional movement screen. The Journal of Strength \& Conditioning Research, 27(4), 982-987. https://doi.org/10.1519/JSC.0b013e3182606df2

Soligard, T., Schwellnus, M., Alonso, J. M., Bahr, R., Clarsen, B., Dijkstra, H. P., \& Engebretsen, L. (2016). How much is too much? (Part 1) International Olympic Committee consensus statement on load in sport and risk of injury. British Journal of Sports Medicine, 50(17), 1030-1041. https://doi.org/10.1136/bjsports-2016-096581

Solomon, R., Solomon, J., Micheli, L. J., \& McGray, E. (1999). The "cost" of injuries in a professional ballet company: a five-year study. Medical Problems of Performing Artists, 14, 164-170.

Van Seters, C., Van Rijn, R. M., Van Middelkoop, M., \& Stubbe, J. H. (2020). Risk factors for lower-extremity injuries among contemporary dance students. Clinical Journal of Sport Medicine, 30(1). https://doi.org/10.1097/JSM.0000000000000533

Wyon, M. A., Abt, G., Redding, E., Head, A., \& Sharp, C. N. (2004). Oxygen uptake during modern dance class, rehearsal, and performance. The Journal of Strength \& Conditioning Research, 18(3), 646-649.

\section{Copyrights}

Copyright for this article is retained by the author(s), with first publication rights granted to the journal.

This is an open-access article distributed under the terms and conditions of the Creative Commons Attribution license (http://creativecommons.org/licenses/by/4.0/). 